Article

\title{
Evaluation of Evacuation Strategies According to the Travel Demand: The Case of Nuclear Research Reactor HANARO's EPZ
}

\author{
Bongseok Kim $^{1}{ }^{\mathbb{D}}$, Hyeonmyeong Jeon ${ }^{2, * \mathbb{D}}$ and Bongsoo Son ${ }^{2}$ \\ 1 Nuclear Emergency Preparedness Team, Korea Atomic Energy Research Institute, 111, Daedeok-daero \\ 989beon-gil, Yuseong-gu, Daejeon 34057, Korea; kbs@kaeri.re.kr \\ 2 Department of Urban Planning and Engineering, Yonsei University, 50 Yonsei-ro Seodaemun-gu, \\ Seoul 03722, Korea; sbs@yonsei.ac.kr \\ * Correspondence: hmjeon15@yonsei.ac.kr
}

Received: 7 July 2020; Accepted: 29 July 2020; Published: 30 July 2020

\begin{abstract}
In the event of a nuclear accident, evacuation is the most effective protective action for the public. During the evacuation, total travel time is a key measure to protect the public because it is directly related to the public's radiation exposure. Thus, strategies that reduce the total travel time are needed for a safer nuclear emergency plan. Many studies on evacuation strategies so far have suggested the methodology of effective routing decisions or delay management. Despite the application of those strategies during evacuation, the effectiveness of those strategies, in reality, varies depending on the level of travel demand. In this study, evacuation strategies based on travel demand levels were evaluated based on the case of the Emergency Planning Zone (EPZ) of HANARO, the nuclear research reactor in the Republic of Korea. As a result, it was confirmed that effective evacuation strategies could be applied differently according to travel demand levels.
\end{abstract}

Keywords: nuclear accident; emergency evacuation; evacuation strategies; travel demand; total travel time

\section{Introduction}

Nuclear energy is considered a clean energy source globally because of its low level of carbon dioxide emissions and high energy efficiency. According to the International Atomic Energy Agency (IAEA), the proportion of nuclear energy sources has increased globally and safety technologies for nuclear energy are being developed steadily [1,2]. Despite its advantages, nuclear energy is still a controversial issue in terms of safety. After the Fukushima accidents in 2011, many environmental groups demanded reinforced safety measures, including the protection of the public who live in the surrounding area of nuclear facilities [3]. Thus, the importance of protective actions for the public increased. Since evacuation is one of the effective protective actions when a nuclear accident happens, studies on evacuation strategies for a nuclear accident should be conducted [4].

The ultimate goal of evacuation is to avoid the deterministic effect and to reduce the probabilistic effect from radiological materials when a nuclear accident happens. Thus, evacuation strategies should be implemented promptly for the public. Urbanik II emphasized that the purpose of the evacuation time estimate was to reduce the radiation exposure of the residents in the Emergency Planning Zone (EPZ) during an emergency situation and to provide decision-makers with information on whether the evacuation strategies are effective [5]. Deng et al. provided guidance for the fastest evacuation after nuclear accidents and emphasized the importance of the evacuation strategy and speed of decision-making [6]. Generally, the measure of effectiveness (MOE) to evaluate the evacuation strategies' adequacy is based on how much evacuation time is reduced. Since the risk and public 
protection methods vary from disaster type, MOE of evacuation strategies are different according to the disaster type [7]. In case of a nuclear accident, it is important to establish evacuation strategies for reducing the total evacuation travel time, which is highly related to radiation exposure. However, in case of other types of disasters, such as volcanic eruptions or tsunamis, threats are visible and predictable. Therefore, evacuation strategies for those types should focus on reducing the clearance time in the affected area rather than total evacuation travel time. MOE can be applied differently for evacuation strategies for each disaster type. Thus, the factors, which are considered during the decision-making process (i.e. the process of evaluating evacuation strategies for public protection), are also different for each disaster type. In this study, evacuation strategies are established for a nuclear accident and by using the total travel time as the MOE.

In an actual evacuation strategy during an accident, the population and travel demand plays a key role in deciding the adequate strategies, because travel time and travel delay depend on the relationship between the travel demand and road network capacity in the EPZ [5]. This means the road network capacity in the affected area is relatively stable whereas the travel demand and population distribution are various. In other words, total travel time is highly subject to travel demand. Besides, it is hard to predict the exact time when an accident occurs and the accurate travel demand in the affected area. Travel demand is not static but dynamic, because the population of the area changes over time, and people keep moving every day for commuting and leisure activities. Furthermore, transit dependent residents, transient populations (people temporarily visiting the area such as tourists, shoppers, and employees who do not reside within the EPZ), and special facilities (such as hospitals, nursing homes, schools, etc.) affect the travel demand of evacuation. Thus, the dynamic of travel demand should be considered in establishing the evacuation strategies, and it should be reflected during the decision-making process.

Studies on evacuation strategies emphasize the importance of travel demand when accidents happen $[5,8,9]$. However, studies on the comparison of the adequacy of evacuation strategies and analysis of the evacuation time differences according to travel demand are relatively insufficient. Studies on traffic control methodology for establishing evacuation strategies are essential to evacuate people who live in the affected area. However, to evaluate the adequacy of each evacuation strategy, a study on analyzing the differences in total travel time according to travel demand is necessary. In this study, the evacuation strategies were established as applied to the common evacuation strategies from previous studies. It was also intended to suggest how the effectiveness of the traffic control strategies depends on the level of travel demand.

\subsection{Evacuation Time and Route}

Evacuation strategies have been studied persistently in order to reduce the public's evacuation time. Urbanik II [5] presented the general methodology for estimating the evacuation time for a nuclear power plant. He presented the basics of the evacuation time estimate, including trip generation and trip distribution. These are related to travel demand and reducing travel time. Here, dispersing the traffic flow is an effective strategy to reduce travel time when there is traffic congestion, although the travel distance could be longer [10]. Zou et al. [11] presented the method for the optimization of the evacuation route in terms of travel time. Considering the road network functions and connectivity is important when designating the evacuation routes. Noh and Do [12] suggested that the roads connected to the major areas of the city and the outside are the most optimal routes for evacuation routes. Therefore, it is important to designate the evacuation route by dispersing travel demand and considering road connectivity.

\subsection{Traffic Control Strategies for Evacuation}

The studies on evacuation strategies have mainly suggested traffic flow control and the operation methodology of traffic networks for reducing the delay time on the road. Kwon and Pitt [13] studied traffic control methods for effective evacuations when an accident occurs in an urban area. 
Using simulations, they analyzed that the evacuation time varies according to the road control method. They compared the method of controlling traffic flowing into the boundary of the downtown area where an accident occurred downtown and the method of increasing road capacity by allowing a contraflow. As a result of the analysis, the evacuation finished more quickly when the capacity of the road network was increased by allowing the contraflow to handle travel demand in the downtown area, rather than simply controlling the traffic entering. This result suggested that the road capacity was important in the evacuation strategy. Edara et al. [14] proposed that the relationship between the road network capacity and travel demand influenced the evacuation time through a comparative analysis of travel demand and throughput traffic. Bottlenecks at the intersections increased the travel time in the evacuation because of queue spill back symptoms and decreased the average travel speed. Besides, studies on evacuation strategies in traffic control, such as the elimination of conflicts at the intersection and lane-based evacuation routing, presented that those strategies are effective at reducing the delays at the intersection $[15,16]$. Son and Jeon [15] suggested that the evacuation time decreases as the number of conflict points at the intersection decreases in the study of the intersectional plan for effective escape from a disaster in a highly concentrated area. In addition, it was suggested that reducing the conflicting points at the intersection is necessary to disperse the travel demand. Cova and Johnson [16] presented the effectiveness of decrease the evacuation time due to the elimination of conflict at intersections, by comparing the shortest distance plan and minimum merging plan.

\subsection{Importance of Information about Emergency and Evacuation Route}

In addition, it is important to notify public about the evacuation routes information for more effective evacuation strategies. Sin et al. [17] presented the need for providing traffic information about detour routes in the event of a disaster on the road and a traffic management strategy through the provision of traffic information. By providing drivers with information on emergency situations and detour information, the total travel distance across the network increased, but the number of vehicles exposed to danger decreased. Yang et al. [18] studied algorithms for providing evacuation and detour route guidance under emergency conditions. This study suggested the need to consider both the evacuation of vehicles in the directly-affected zone of the emergency and the traffic control strategies of indirectly-affected zones at the same time. On the other hand, notifications about accident and evacuation route information might have an influence on evacuation strategies because of individual behavior and decision-making conversion $[8,19,20]$.

This study, however, emphasizes the establishment of evacuation strategies according to travel demand in terms of systems rather than individuals. It is assumed that individuals in the EPZ followed the evacuation strategies because the goal of this study is the comparison of evacuation strategies on traffic control methodology and evacuation routing. The education and exercise drills about evacuation should be implemented before the accident for effective evacuation [21].

The simulation analysis was conducted based on the real road network in the EPZ of a nuclear research reactor to evaluate the effectiveness of each evacuation strategy according to travel demand in a nuclear accident. The spatial area of this study was the EPZ of HANARO. HANARO is a multi-purpose research reactor that is operated by the Korea Atomic Energy Research Institute (KAERI). KAERI has also established the EPZ for any radiological emergency. The EPZ includes densely populated areas such as apartment complexes and other residences [22].

\section{Materials and Methods for Network Analysis}

The PTV VISSIM 7 traffic simulation tool was used to estimate the evacuation time of residents in the EPZ of HANARO. VISSIM has been widely used by many researchers on evacuation and assessing traffic conditions and road networks $[10,14,23]$. VISSIM is the simulation software for the microscopic traffic flow analysis and is suitable for comparing traffic conditions according to travel demand. This tool has the advantages of being able to build up a road network, to set up the travel demand by simulation time, and to collect the section travel time data. To build road network data, 
the road network's characteristics such as the geometric structure of the road, saturation flow rate, number of lanes, and lane width need to be inputted. In addition, these data were collected from satellite images and local government databases. Furthermore, in this study, road network data were not only built in the EPZ area, but outside the EPZ area because evacuations do not only happen in the $\mathrm{EPZ}$ area. Evacuations will be conducted from the EPZ area to the aid station.

\subsection{Evacuation Strategies}

The assessment process of the resident evacuation strategy in a nuclear accident is as shown in Figure 1. Here, the basic elements of evaluating evacuation strategies include the demand for evacuation, accident scenarios, and transportation modeling.
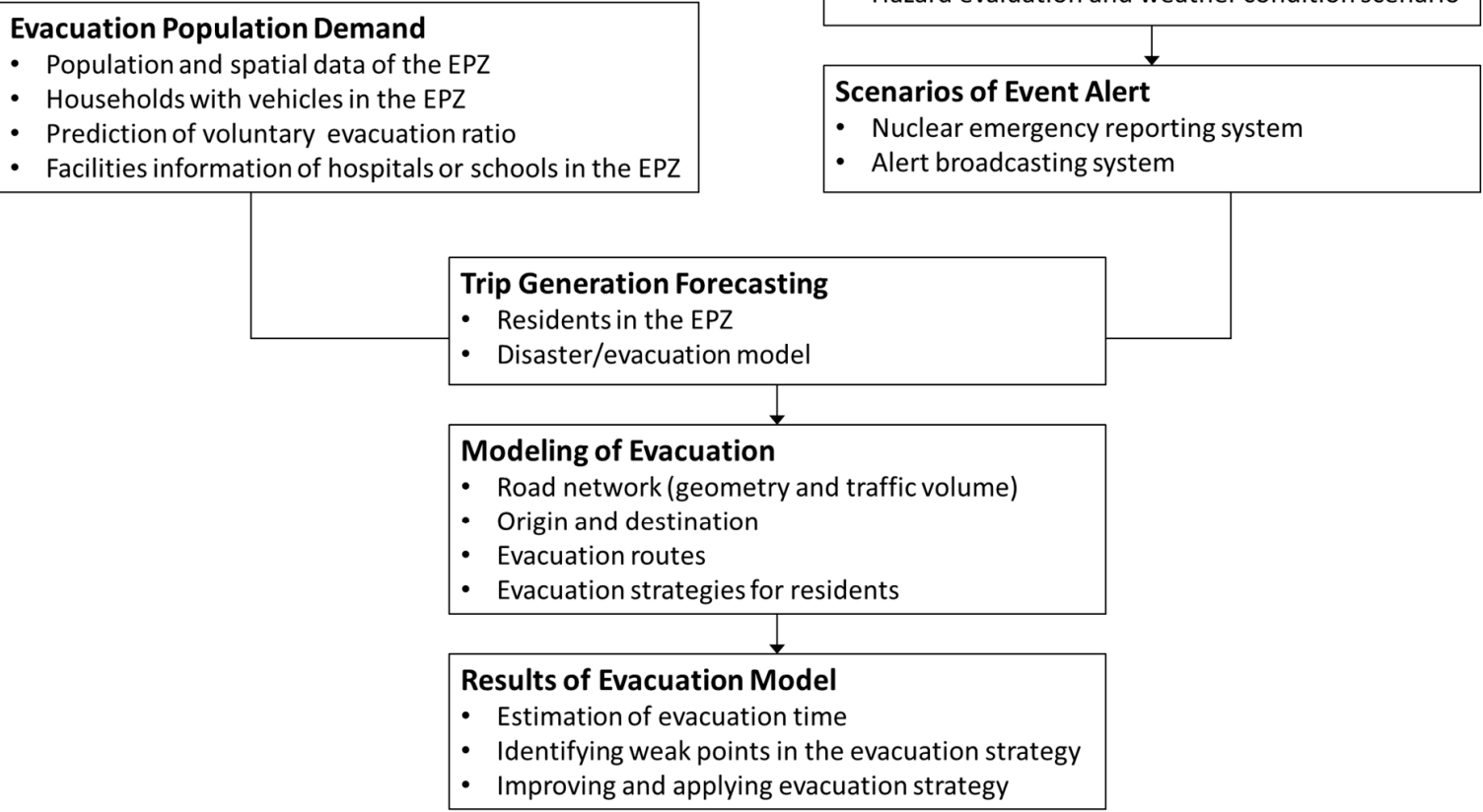

Figure 1. Evacuation time evaluation process.

Residents in EPZ are required to move to the Daejeon Convention Center, which is located approximately $6 \mathrm{~km}$ from HANARO, as a shelter in the case of a nuclear accident. For this purpose, it was assumed that the main roads and networks for evacuating to the Daejeon Convention Center were established and that people could evacuate through a given route (Figure 1). Knowing the location of shelters and moving to a defined route through evacuation drills has a positive impact on evacuation [21]. This is because when the residents evacuate, it is possible for traffic control such as traffic signals at intersections to be performed more efficiently if the residents travel along a given route rather than a random selection of routes (Figure 2).

In the event of a nuclear accident, the evacuation of residents in the EPZ begins, and vehicles are prohibited from entering the EPZ. In addition, for the rapid evacuation of residents, there was no additional trip generation in the entire network, including the evacuation route, immediately after the accident, and a strategy was devised to change the route so that vehicles that had previously traveled in the network moved out of the network. This is an essential strategy for residents to move safely and quickly to their destinations.

In order to distribute the travel demand of the EPZ, the vehicles in area A were set to use the route marked in red, and the vehicles in area B were set to use the route in blue in Figure 1. These routes can disperse the travel demand in the EPZ, have high connectivity with the road network in the EPZ, 
and allow reaching its destinations without conflict with each other. Evacuation routes and traffic control strategies connecting A and B areas and outside EPZ were applied to this study.

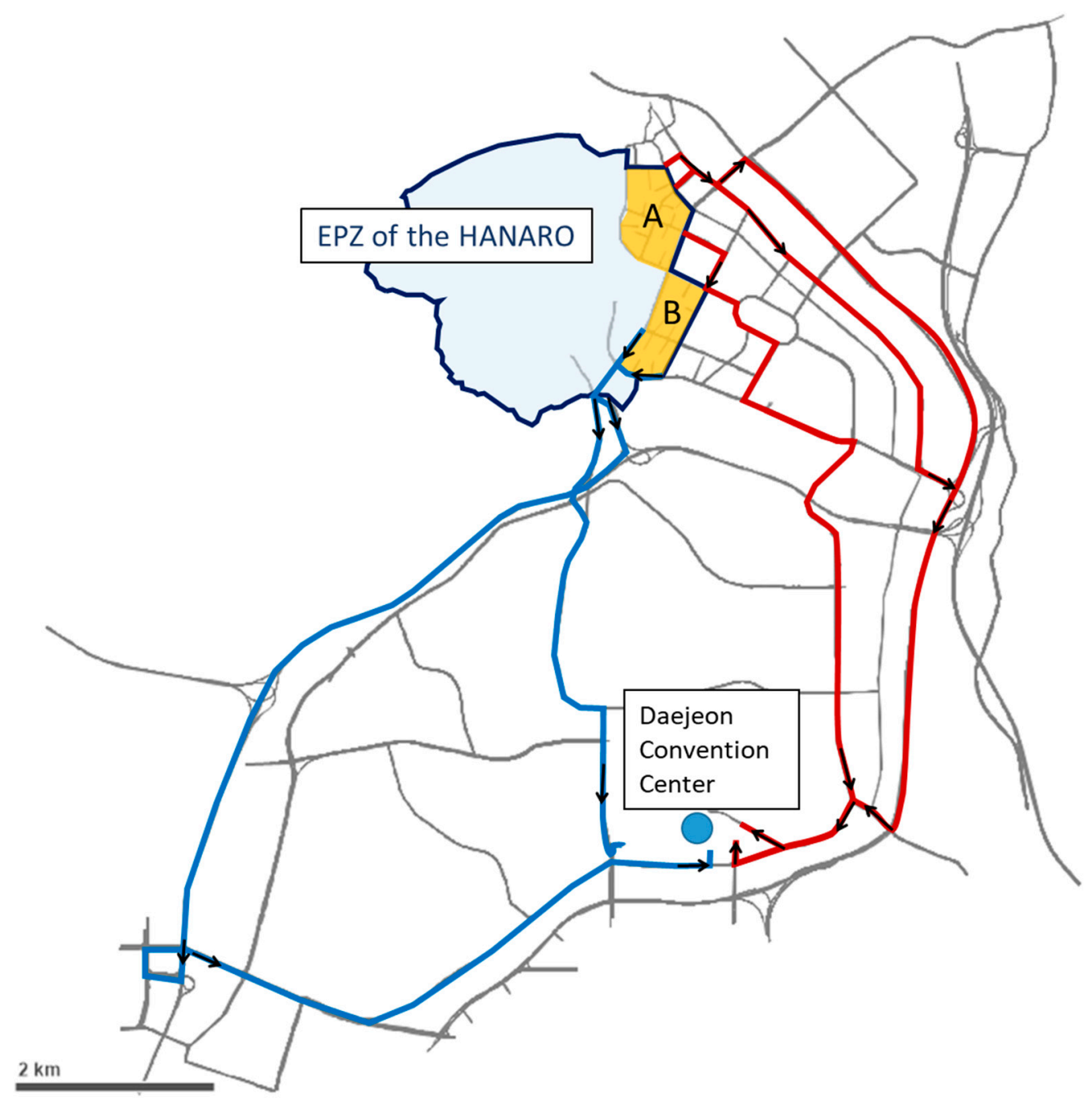

Figure 2. Emergency Planning Zone (EPZ) of HANARO and the road network.

The following are some of the ways that can be considered when developing evacuation strategies.

- Signal timing control to adjust the specific direction's signal time for better traffic flow. In a nuclear accident, signal time of the direction to outside the EPZ is longer than the others, and adjustment of the signal phases according to the traffic flow rates of each direction [8].

- Traffic flow conflict elimination is a basic strategy for controlling the traffic flow at the intersection: it is a method of detouring the direction to eliminate conflicts going in different directions. It is effective not only in reducing the delays but in reducing the risk of traffic accidents $[8,15,16]$.

- Allowing contraflow during the evacuation can increase the road network capacity $[8,13,23]$. This strategy has a significant effect to reduce the evacuation time. However, this strategy cannot be used in a case where traffic in the opposite direction is required. In the event of an accident, supporting and relief vehicles should enter the accident site; therefore, the condition of the road network should be taken into account to decide whether to allow contraflow.

- Staged evacuation is to implement evacuation assignments to minimize evacuation time. The severely affected area, such as nearer area from the accident site, evacuate first and the others evacuate sequentially. Public compliance with this strategy is important to make it effective. Lower than anticipated compliance will affect the performance of this strategy $[8,9]$. 
These strategies can be used in developing evacuation strategies such as detoured routing and traffic control. However, in this study, evacuation scenarios were set up by adopting the traffic conflict control and signal time control, considering the realistic environment that can be applied to the spatial scope of the study. Contraflow strategies are not applicable in this area because of the characteristics of the road network in the spatial range of this study. The study site is a densely residential area with short distances between intersections, and the roads have a small number of lanes because these are composed of collectors and local roads. Furthermore, under staged evacuation strategies, compliance with the public's evacuation strategies is more important than travel demand and traffic control. Thus, a staged evacuation strategy is not applicable to this study.

Evacuation strategies were divided into scenario 1 and scenario 2 . The scenarios depended on the route plan in the EPZ from their home to the main evacuation route. Scenario 1 is related to a signal time control strategy, and scenario 2 is related to a strategy to eliminate traffic flow conflicts and to designate detour routes. Figure 3 shows the evacuation route in Scenario 1, and Figure 4 shows the evacuation route in Scenario 2. The number of origin points for trip generation was composed of 18 points for evacuation time estimate modeling. These origin points were selected as points that match the entry points of the EPZ's residential area.

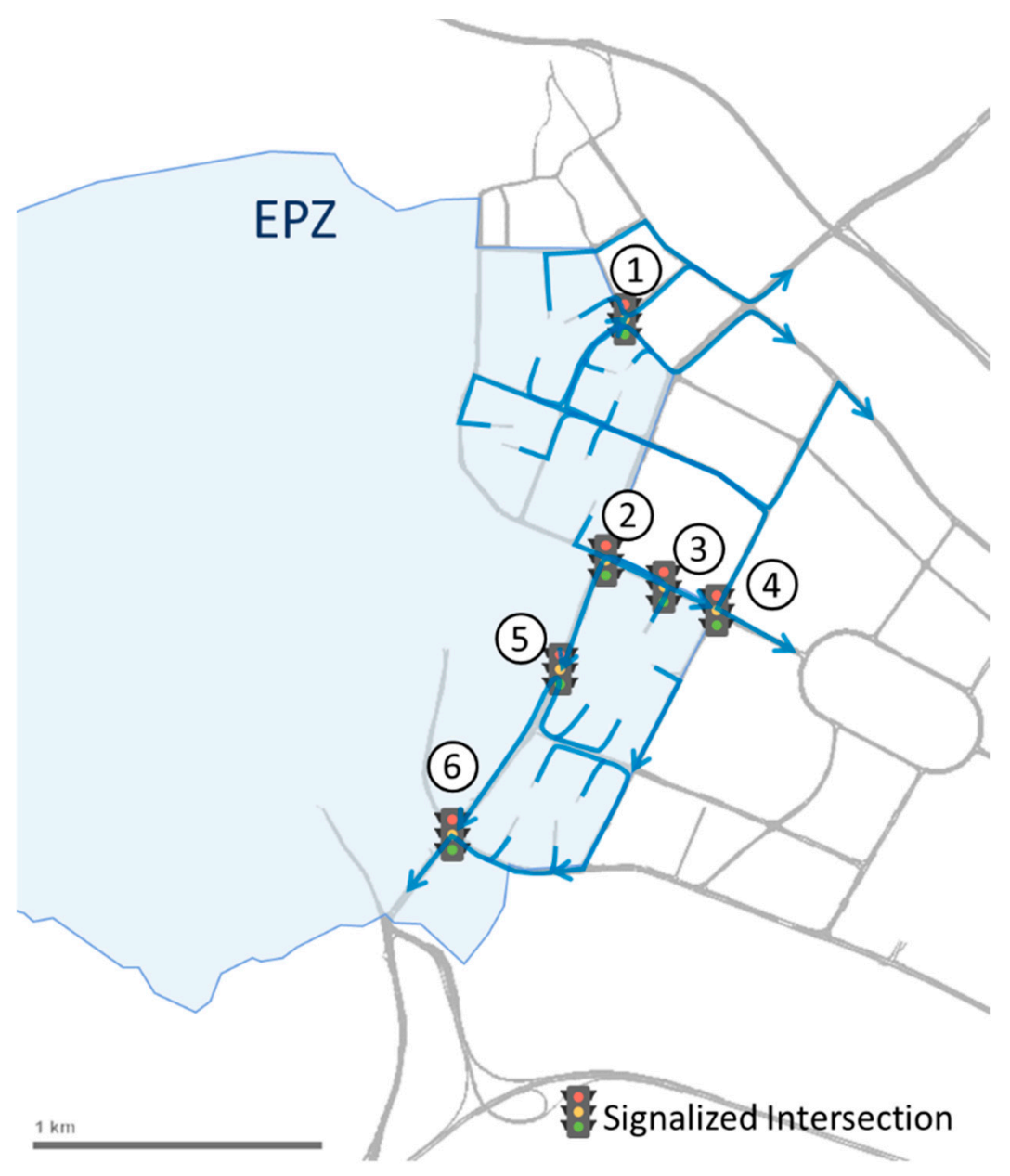

Figure 3. Evacuation Routes of Scenario 1. 


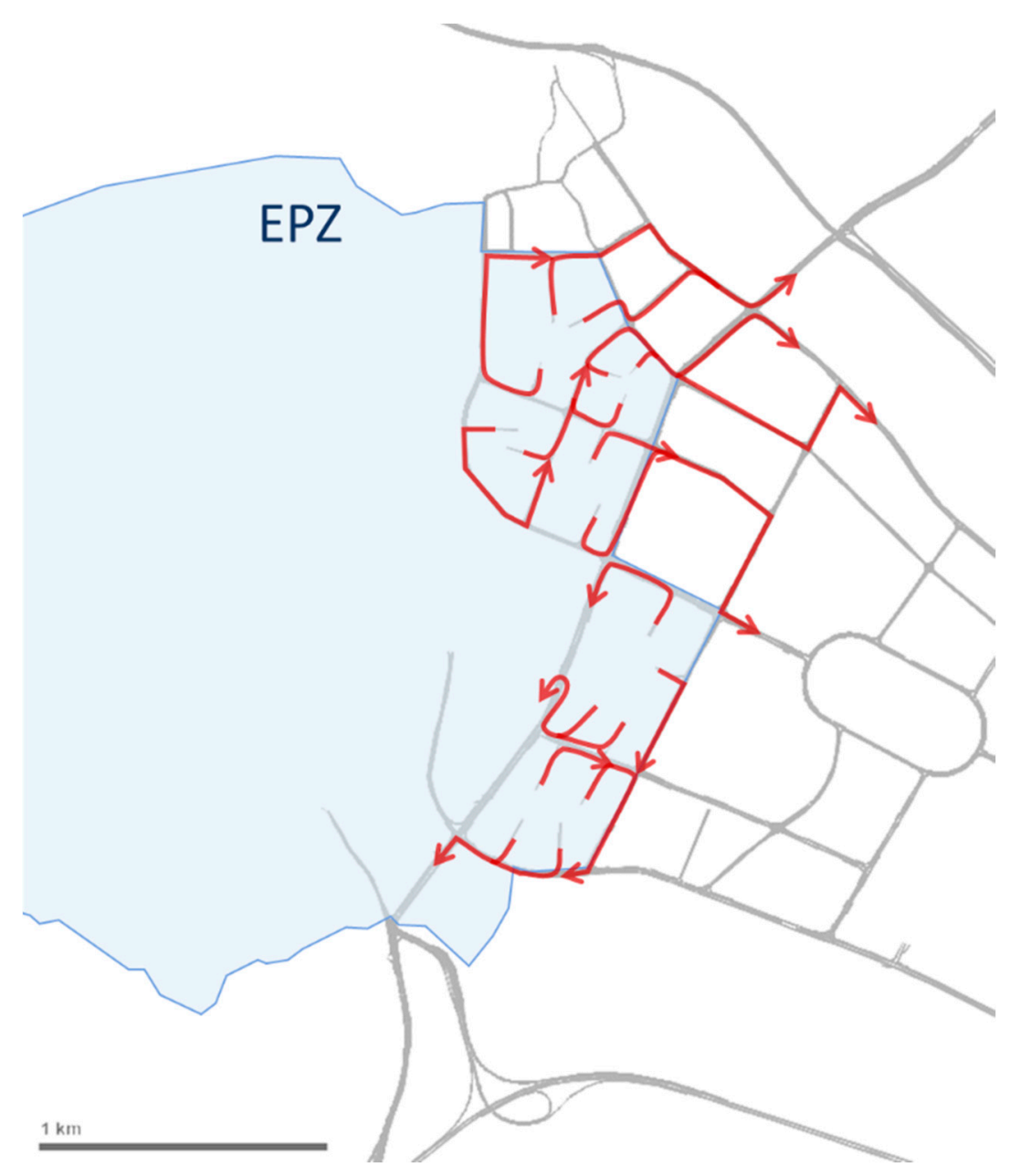

Figure 4. Evacuation Route of Scenario 2.

\subsubsection{Scenario 1: Shortest Path with Signals}

In Scenario 1, the evacuation route was set to exit the EPZ in the shortest distance and to several routes that could distribute the traffic flow. When traffic flows along the shortest route, several conflicts arise at the intersection. Traffic flow control through the traffic signal is necessary at intersections where straight vehicles and left-turn vehicles cause crossing conflicts. Therefore, in this scenario, the vehicles at the signal intersection traveled with an interrupted flow.

The signal intersection was assumed to be optimized according to the traffic volume ratio in each direction, and the signal phases were assigned every $120 \mathrm{~s}$ according to the traffic ratio (Figure 5). Signal phases according to the traffic volume in each direction operated as a fixed signal. As shown in Figure 2, a total of six signalized intersections in the EPZ were required for evacuation. At the intersections of No. 2 and No. 3, crossing conflicts occurred between the straight vehicles and left-turn vehicles, and at the intersections of No. 1, No. 4, No. 5, and No. 6, merging conflicts occurred. 


\begin{tabular}{|c|c|c|c|c|}
\hline & Phase & Direction & Ratio & $\begin{array}{c}\text { Green Time } \\
(\mathrm{sec})\end{array}$ \\
\cline { 2 - 5 } 1 & $\mathrm{~A}$ & $\uparrow$ & 0.38 & 46 \\
\cline { 2 - 5 } & B & $\uparrow$ & 0.62 & 74 \\
\hline
\end{tabular}

\begin{tabular}{|c|c|c|c|c|}
\hline & Phase & Direction & Ratio & $\begin{array}{c}\text { Green Time } \\
(\mathrm{sec})\end{array}$ \\
\cline { 2 - 5 } 4 & $\mathrm{~A}$ & $\longrightarrow$ & 0.60 & 72 \\
\cline { 2 - 5 } & $\mathrm{B}$ & $\longrightarrow$ & 0.40 & 48 \\
\hline
\end{tabular}

\begin{tabular}{|c|c|c|c|c|}
\hline & Phase & Direction & Ratio & $\begin{array}{c}\text { Green Time } \\
(\mathrm{sec})\end{array}$ \\
\cline { 2 - 5 } 2 & $\mathrm{~A}$ & $\longrightarrow$ & 0.80 & 96 \\
\cline { 2 - 5 } 2 & $\mathrm{~B}$ & $\sqrt{ }$ & 0.20 & 24 \\
\hline
\end{tabular}

\begin{tabular}{|c|c|c|c|c|}
\hline & Phase & Direction & Ratio & $\begin{array}{c}\text { Green Time } \\
(\mathrm{sec})\end{array}$ \\
\cline { 2 - 5 } 5 & A & $\downarrow$ & 0.11 & 13 \\
\cline { 2 - 5 } & B & $\downarrow$ & 0.89 & 107 \\
\hline
\end{tabular}

\begin{tabular}{|c|c|c|c|c|}
\hline \multirow{3}{*}{3} & Phase & Direction & Ratio & $\begin{array}{c}\text { Green Time } \\
(\mathrm{sec})\end{array}$ \\
\cline { 2 - 5 } & $\mathrm{A}$ & $\longrightarrow$ & 0.58 & 70 \\
\cline { 2 - 5 } & & $\longleftarrow$ & 0.42 & 50 \\
\hline
\end{tabular}

\begin{tabular}{|c|c|c|c|c|}
\hline \multirow{4}{*}{6} & Phase & Direction & Ratio & $\begin{array}{c}\text { Green Time } \\
(\mathrm{sec})\end{array}$ \\
\cline { 2 - 5 } & $\mathrm{A}$ & $\downarrow$ & 0.30 & 36 \\
\cline { 2 - 5 } & $\mathrm{B}$ & $\downarrow$ & 0.70 & 84 \\
\hline
\end{tabular}

Figure 5. Signal phases in scenario 1.

\subsubsection{Scenario 2: Detour routes}

In the strategy of exiting the EPZ in the shortest distance (scenario 1), a control delay was caused by traffic signals. Here, control delay means the delay that results when a traffic control device (such as traffic signal) causes traffic movement to reduce speed or to stop [24]. In scenario 2, evacuation detour routes were set so that there was no control delay. In the evacuation route in Scenario 2, only merging conflicts occurred between the straight vehicles and the right-turn vehicles. This merging was not controlled by the signals, unlike the conflict caused by the confluence of straight vehicles and left-turn vehicles. Even in this scenario, there was a left-turn merging to exit the origin and a U-turn merging point, but it was assumed that the vehicles merged without a traffic signal. Thus, in scenario 2, the vehicles passed all intersections without signal control and control delay. However, if the evacuation vehicles moved to the detour routes to avoid conflict, there would be no control delay, but a longer travel distance and more turning.

Scenarios 1 and 2 differ in the main causes of delay. In scenario 1, if the control delay caused by the traffic signal is the main delay factor; then in scenario 2, the delay at the merging point is the major delay factor. Depending on the evacuation strategy for each scenario, the road capacity (i.e., maximum throughput) that can be processed in the road network varies. In scenario 1, the capacity of the signal intersections and the capacity at the main merging point determine the capacity of the entire evacuation path. In scenario 2 , the evacuation route capacity is determined by merging the bottleneck at more points. In general, the number of straight lanes is greater than the number of turn lanes on a roadway. Therefore, to make the straight traffic flow efficient, the capacity of the signal intersection is greater than the detour path, but the signal causes unnecessary control delay in the traffic flow below the capacity. The efficiency of the signal operation strategy and the detour strategy varies depending on the evacuation routes and the travel demand for each route. To evaluate the efficiency, the total travel time was compared to the changes in travel demand for each scenario. 


\subsection{Simulation}

Vehicles passing through the network before evacuation began (i.e., background traffic) were set using the peak hour transportation demand in 2015 from the origin-destination (OD) data by major modes of the Daejeon metropolitan area (2013-2040) [25]. Background traffic was generated for $1 \mathrm{~h}$ after the start of the simulation. Then, assuming that an emergency situation occurred at $1 \mathrm{~h}$ after the simulation start, evacuation was set to start thereafter. In other words, background traffic was generated for each zone inside and outside the EPZ for $1 \mathrm{~h}$ after the start of the simulation, and if an accident occurred thereafter, traffic control started in the network according to the evacuation strategy. In scenario 1 , the signal systems for evacuation also worked at $1 \mathrm{~h}$ after the start of the simulation.

In order to compare the effects of each scenario on travel demand, the total number of residents' vehicles subject to evacuation increased by 2000 vehicles from 12,000 to 24,000 vehicles. Then, the evacuation times were compared by the level of demand. Here, it was assumed that the travel demand was inputted by zone, and the trip was uniformly generated for $120 \mathrm{~min}$. To simulate the actual expected evacuation pattern according to the inhabited population and traffic volume, the travel demand for each zone was divided and the input was based on the population ratio of the actual residents.

\section{Results}

The effectiveness of the evacuation strategy was represented by the total travel time of the residents' vehicles. The shorter the travel time, the more effective the evacuation strategy was and the less radiation exposure the residents encountered. To compare the effects of evacuation strategies by scenario, the total travel time and total delay were estimated. In order to analyze the difference in total travel time and total delay according to travel demand, the travel time data from the origin zones to the EPZ boundary were collected. The reason for comparing the travel time to the EPZ boundary rather than the final destination was that the EPZ had a range of dangers affected by radiation, so it was determined that the residents were released from the radiation risks as soon as they left the EPZ. Here, the residents escaped the EPZ and moved to the final destination, the Daejeon Convention Center, but the travel time for this route was not included in the analysis data. However, due to the spillback occurring in the path from the EPZ boundary to the destination, the travel time in the EPZ could increase. Delays due to this spillback were considered in estimating the travel time.

Table 1 shows the results of analyzing the estimated evacuation time data. From these results, it can be seen that, regardless of the scenarios, the total travel time increased as the total delay increased. The total delay refers to the difference between the actual travel time and the travel time at a free-flow speed. The total travel time was interpreted as the effect of the delay rather than the scenario-specific distance of the evacuation routes because the distance from the departure zone to the EPZ boundary was short. When comparing the total travel time of 12,000,14,000, and 16,000 vehicles, it was found that scenario 2 had a smaller total travel time value than scenario 1 . Conversely, the total travel time for scenario 1 was less when the estimation travel demand was over 18,000.

In scenario 2, the vehicles traveled longer distances as they bypassed the detour route, and thus, they experienced many turns. In the road network, the intersection lanes were mostly composed of one or two turn lanes, and the number of lanes decreased compared to the straight lanes, so the capacity of the turn lanes was significantly less than that of the straight lanes. As the number of lanes decreased, the vehicles experienced bottlenecks on the turn lanes. When this bottleneck occurred, the delay increased, and the vehicles in scenario 2 turned more and experienced more bottlenecks. When the evacuation demand was less than 16,000 vehicles, scenario 2 was more effective than scenario 1 because the control delay by the signal was greater than the bottlenecks caused by the turn lanes. However, when the evacuation demand increased to 18,000 vehicles or more, delays due to bottlenecks were greater than the control delays caused by signals. 
Table 1. Summary of travel time and delay.

\begin{tabular}{ccccccc}
\hline $\begin{array}{c}\text { Evacuation } \\
\text { Demand } \\
\text { (veh) }\end{array}$ & $\begin{array}{c}\text { Total Travel } \\
\text { Time } \\
\text { (veh·s) }\end{array}$ & $\begin{array}{c}\text { Average } \\
\text { Travel Time } \\
\text { (s) }\end{array}$ & $\begin{array}{c}\text { Total Delay } \\
\text { (veh·s) }\end{array}$ & $\begin{array}{c}\text { Total Travel } \\
\text { Time } \\
\text { (veh·s) }\end{array}$ & $\begin{array}{c}\text { Average } \\
\text { Travel Time } \\
\text { (s) }\end{array}$ & $\begin{array}{c}\text { Total Delay } \\
\text { (veh.s) }\end{array}$ \\
\hline 12,000 & $2,306,639$ & 196.7 & $1,354,178$ & $1,150,506$ & 98.0 & 51,512 \\
\hline 14,000 & $3,435,499$ & 250.6 & $2,318,318$ & $2,356,527$ & 172.0 & $1,072,548$ \\
\hline 16,000 & $4,257,576$ & 270.3 & $2,973,794$ & $4,239,583$ & 269.8 & $2,768,979$ \\
\hline 18,000 & $5,574,537$ & 315.8 & $4,136,583$ & $6,479,454$ & 369.5 & $4,839,431$ \\
\hline 20,000 & $7,022,361$ & 357.6 & $5,422,274$ & $7,979,895$ & 408.5 & $6,154,976$ \\
\hline 22,000 & $8,286,639$ & 382.9 & $6,524,097$ & $9,977,881$ & 462.8 & $7,965,176$ \\
\hline 24,000 & $9,901,588$ & 420.2 & $7,983,565$ & $11,833,266$ & 503.7 & $9,639,657$ \\
\hline
\end{tabular}

\section{Discussion and Conclusions}

Travel demand is recognized as a factor of a significant impact on evacuation strategies. This study proves the importance of the relationship between travel demand and evacuation strategies by comparing the impacts of travel demand to evacuation time according to strategies. Total travel time is the MOE of this study for the evaluation of the evacuation strategies, which has a high relationship with radiation exposure during a nuclear accident. Furthermore, this study conducted a simulation-based analysis on the actual road network. As a result, effective traffic control strategies could change depending on the travel demand level.

In the case of the detoured traffic flow strategy, it was more effective in demand levels between 12,000 and 16,000 vehicles, which means the travel demand level was relatively low in this study because there was no control delay due to a signal. However, it was analyzed that the shortest path evacuation strategy with a signalized intersection was a more effective strategy than detours at the travel demand levels between 18,000 and 24,000 vehicles. The results of this study suggest that effective evacuation strategies could vary depending on the configuration of the traffic network and travel demands, which are traffic characteristics. The traffic network capacity of evacuation routes depends on the signal phases and the number of lanes for each direction at the main intersections. Therefore, in the decision-making process of evacuation strategy, it is important to know in advance the maximum traffic flow rate for each major direction according to the traffic network and the evacuation route. In addition, an appropriate travel demand distribution strategy according to demand level is needed. Furthermore, effective evacuation based on the emergency plan will be possible only if the information on the evacuation route and the rapid communication of the accident along with a traffic control strategy are supported.

Since the characteristics of the road network differ depending on the region, the regional throughput traffic volumes vary by region. This study demonstrated that the effect of the signal control and detour route strategies has different impacts from the travel demand level. The result of this study can be used as a basis for decision-making in various target areas. In addition, travel demand in evacuation cannot be accurately predicted, thus, it is effective to validate the strategies under various demand conditions.

Nuclear accidents that require the evacuation of the public from the surrounding area will occur differently based on circumstance. Thus, the application of evacuation strategies could change dynamically based on the situation of the surrounding area. Developing an appropriate strategy according to the travel demand can be effective not only for a nuclear accident but also for an evacuation plan for other disaster types. The reason is that it can prepare for the changing evacuation travel demand due to the fluctuation of tourism and visiting demands. The evaluation of an evacuation strategy according to travel demand level could be a key reference for the decision-making of evacuation strategies in any kind of emergency in the future. 
Author Contributions: Conceptualization, methodology: B.K., H.J. and B.S.; formal analysis: B.K. and H.J.; writing-original draft preparation: B.K. and H.J.; writing-review and editing: B.K., H.J. and B.S. All authors have read and agreed to the published version of the manuscript.

Funding: This research was funded by the Nuclear R\&D program of the Ministry of Science and ICT, Republic of Korea.

Acknowledgments: This research has been conducted as a part of the project of emergency preparedness for nuclear research facilities in KAERI.

Conflicts of Interest: The authors declare no conflict of interest.

\section{References}

1. Brook, B.W.; Bradshaw, C.J.A. Key role for nuclear energy in global biodiversity conservation. Conserv. Biol. 2015, 29, 702-712. [CrossRef] [PubMed]

2. International Atomic Energy Agency (IAEA). Available online: https://www.iaea.org/newscenter/news/iaeareleases-2019-data-on-nuclear-power-plants-operating-experience (accessed on 30 June 2020).

3. United States Nuclear Regulatory Commission (U.S.NRC). Available online: https://www.nrc.gov/reactors/ operating/ops-experience/post-fukushima-safety-enhancements.html (accessed on 30 June 2020).

4. Malešič, M.; Prezelj, I.; Juvan, J.; Polič, M.; Uhan, S. Evacuation in the event of a nuclear disaster: Planned activity or improvisation? Int. J. Disaster Risk Reduct. 2015, 12, 102-111. [CrossRef]

5. Urbanik, T., II. Evacuation time estimates for nuclear power plants. J. Hazard. Mater. 2000, 75, 165-180. [CrossRef]

6. Deng, Y.; Zou, S.; You, D. Theoretical Guidance on Evacuation Decisions after a Big Nuclear Accident under the Assumption That Evacuation Is Desirable. Sustainability 2018, 10, 3095. [CrossRef]

7. Han, L.D.; Yuan, F.; Urbanik, T., II. What Is an Effective Evacuation Operation? J. Urban Plan. Dev. 2007, 133, 3-8. [CrossRef]

8. Murray-Tuite, P.; Wolshon, B. Evacuation transportation modeling: An overview of research, development, and practice. Transp. Res. Part C Emerg. Technol. 2013, 27, 25-45. [CrossRef]

9. Jones, J.; Walton, F.; Wolshon, B. Criteria for Development of Evacuation Time Estimate Studies; United States Nuclear Regulatory Commission: Washington, DC, USA, 2011.

10. Elmitiny, N.; Ramasamy, S.; Radwan, E. Emergency Evacuation Planning and Preparedness of Transit Facilities: Traffic Simulation Modeling. Transp. Res. Rec. 2007, 1992, 121-126. [CrossRef]

11. Zou, Y.; Zou, S.; Niu, C. The Optimization of Emergency Evacuation from Nuclear Accidents in China. Sustainability 2018, 10, 2737. [CrossRef]

12. Noh, Y.; Do, M. Determination of Emergency Evacuation Roads Considering Road Network Function and Connectivity. J. Korea Inst. Intell. Transp. Syst. 2014, 13, 34-42. [CrossRef]

13. Kwon, E.; Pitt, S. Evaluation of Emergency Evacuation Strategies for Downtown Event Traffic Using a Dynamic Network Model. Transp. Res. Rec. 2005, 1922, 149-155. [CrossRef]

14. Edara, P.; Sharma, S.; McGhee, C. Development of a Large-Scale Traffic Simulation Model for Hurricane Evacuation-Methodology and Lessons Learned. Nat. Hazards Rev. 2010, 11, 127-139. [CrossRef]

15. Son, Y.; Jeon, J. A Study on The Intersectional Plan for Effective Escape in the Case of Social Disaster in the Population Concentration Area. J. Korean Soc. Transp. 2019, 37, 66-77. [CrossRef]

16. Cova, T.J.; Johnson, J.P. A network flow model for lane-based evacuation routing. Transp. Res. Part A Policy Pract. 2003, 37, 579-604. [CrossRef]

17. Sin, S.; Jo, Y.; Lee, C. Strategies for Providing Detour Route Information and Traffic Flow Management for Flood Disaster. J. Korean Soc. Transp. 2007, 25, 33-42.

18. Yang, C.; Son, Y.; Yang, I.; Kim, H. Developing algorithms for providing evacuation and detour route guidance under emergency conditions. Int. J. Highw. Eng. 2009, 11, 129-139.

19. Dash, N.; Gladwin, H. Evacuation Decision Making and Behavioral Responses: Individual and Household. Nat. Hazards Rev. 2007, 8, 69-77. [CrossRef]

20. Tan, L.; Wu, L.; Lin, H. An individual cognitive evacuation behaviour model for agent-based simulation: A case study of a large outdoor event. Int. J. Geogr. Inf. Sci. 2015, 29, 1552-1568. [CrossRef]

21. Lee, D.; Yoon, S.; Park, E.; Kim, Y.; Yoon, D.K. Factors Contributing to Disaster Evacuation: The Case of South Korea. Sustainability 2018, 10, 3818. [CrossRef] 
22. Kim, B.; Lee, G. Development of evacuation time estimates on research reactor 'HANARO'. In Proceedings of the European Research Reactor Conference (RRFM), Berlin, Germany, 13-17 March 2016; European Nuclear Society: Brussels, Belgium, 2016; pp. 379-386.

23. Ekram, A.-A.; Rahman, M.S. Effects of Connected and Autonomous Vehicles on Contraflow Operations for Emergency Evacuation: A Microsimulation Study. In Proceedings of the Transportation Research Board 97th Annual Meeting, Washington, DC, USA, 7-11 January 2018.

24. Transportation Research Board. Highway Capacity Manual 6th Edition: A Guide for Multimodal Mobility Analysis; Elefteriadou, L.A., Ed.; The National Academies Press: Washington, DC, USA, 2016; Volume 3, Chapter 19; p. 11.

25. Korea Transport DataBase (KTDB). The Korea Transport Institute. Data Name Is 2014-OD-PSN-MOD-14. Available online: https://www.ktdb.go.kr/www/contents.do?key=24 (accessed on 15 April 2020).

(C) 2020 by the authors. Licensee MDPI, Basel, Switzerland. This article is an open access article distributed under the terms and conditions of the Creative Commons Attribution (CC BY) license (http://creativecommons.org/licenses/by/4.0/). 